\title{
Study on Peasants' Participation in the Rural Minimum Living Standard Guarantee System
}

\author{
Yining DING \\ School of law, politics \& public administration \\ Hebei normal university \\ Shijiazhuang, HEBEI, P.R.China
}

\author{
Yongzhi GENG* \\ School of law, politics \& public administration \\ Hebei normal university \\ Shijiazhuang, HEBEI, P.R.China
}

\begin{abstract}
The operation of the Rural Minimum Living Standard Guarantee System and the degree of participation of the main body are relatively poor in most areas of China nowadays, and there exist several problems (e.g., the confusion of the definition, the deviation of policy implementation as well as the lack of effective management means). The management of government alone has been unable to gain the peasants' trust and meet their demand. The aim of this study is to avoid the deficiencies of rural subsistence allowance that under the traditional management mode, improve the Rural Minimum Living Standard Guarantee System to be opener and more rational, help peasants to better understand the rural subsistence allowance policy, dispel their concerns, and increase social participation by the participation of peasants. However, peasants' participation cannot solve all the problems but negatively affect the construction of the Rural Minimum Living Standard Guarantee System. This probably results from peasants' interests becoming self-oriented, their unordered participation and self-preference, etc. In practice, we should avoid both the deficiencies above and seek the conjunction from government management and peasants' participation to facilitate the construction of modern governance model and service-oriented government.
\end{abstract}

Keywords-Social governance; peasant participation system; Rural Minimum Living Security; Service oriented government; co-operative governance; Participatory democracy

\section{INTRODUCTION}

In recent years, the government has paid increasing attention to the study on target groups when they make a policy. The governance mode is shifting from single management-oriented social governance to the diversified service-oriented social governance. [1] As an important tool for maintaining social stability, the formulation and implementation of the Rural Minimum Living Standard Guarantee System should also change with the times. Under the service-oriented social governance, development strategy of the rural subsistence allowances system can be defined as the close association of various social governance roles, launching the governance based on "services".

The academic circles conducted some studies on peasants' participation in the construction of the Rural Minimum Living Standard Guarantee System. Some experts hold that peasants' participation is of great significance when selecting household enjoying the minimum living guarantee. Ban Tao (2017) thought that the strength of the local was very important in the process that the subsistence object is aimed at China. He suggested that building a full information network was the prerequisite for the effectiveness of local strength. Some experts start with social organizations, holding that peasants' participation based on social organizations is a strong complement to the construction and implementation of Rural Minimum Living Standard Guarantee System. Xiang Deping and his team (2014) believe that introducing social organizations to participate in to the control of the rural poverty, undertake some social services. It can help reduce government service cost, expand the scope of policy implementation, consolidate the effectiveness of poverty alleviation; Yang Xinxin (2017) introduced the idea of Western deliberative democracy. He believed that we can limit the abuse of power by the government through full discussion between basic level government and the villagers, the evaluation and negotiate maximization, to provide an effective way to establish a corrective mechanism for the Rural Minimum Living Standard Guarantee system.

Most scholars hold a positive attitude towards peasants' participation in the construction of the Rural Minimum Living Standard Guarantee System, but there are also opposing views. Yin Zi (2014) thought that simply peasants' participation does not consider the social foundation of the countryside. In the process of democratic appraisal, it is just a theoretical pursuit that takes more people vote for fairness; it does not follow the actual situation of the village society.

In brief, the study on this aspect remains in its infancy, lacking systematic and in-depth research. The research perspective is primarily in the correction of policies and supplement household enjoying the minimum living guarantee authentication mechanism. It seems singleness, the proposed countermeasures also show empty, lacking the analysis from the perspective of complementation and the participation model.

In this study, from the perspective of the participatory democracy and service-oriented government construction, the policy development department, basic level policy implementation department, village self-government bodies and the weak population of society are interconnected to provide services to each other.. In the pursuit of "people-oriented", more government plans with a sense of identity and binding force are formed with the goal of "publicity" and "pertinence" in pursuit of the overall interests of the society, thereby achieving the optimal allocation of resources.

Fund Project: National Social Science Fund Project "Study on the Ethical Path of Rural Social Governance” (Project No: 16BZX100) 


\section{The Main Problems of the CuRrent RuRal Minimum} Living STANDARD GUARANTEE SYSTEM

\section{A. Insufficient Accuracy Defined by Household Enjoying the Minimum Living Guarantee}

1) Difficulties in accurate statistics of peasants' income.

Nowadays peasants have various income sources. The proportion of wage income in rural households has risen significantly. However, peasants rarely sign labor contracts with companies, the wage income is highly changed, and payment of wages is complicated. Thus, statistics are very complicated. In addition, many farmers are reluctant to disclose their real income because they are in the state of self-protection.

2) Statistical high cost of peasants' income, Lack of a sound income accounting system.

The grass-roots civil servant themselves have heavy tasks, tight working hours and are short of manpower, so it is difficult to allocate manpower to carry out the income statistics of farmers independently. Moreover, there is no perfect income accounting system and information sharing mechanism. It's easy to make mistakes and impact the validity of the audit. ${ }^{[2]}$

3) The level of evaluation of household enjoying the minimum living guarantee is insufficient, and it is difficult to define fairness.

Some evaluations of household enjoying the minimum living guarantee are not well educated and cannot understand the policy completely. Traditional "coterie" type of ethical thinking often serves as the criterion of judgment, and the main object of consideration is the sects, acquaintances and their own interests.

\section{B. Execution Bias of the Rural Minimum Living Standard Guarantee System}

1) The evasiveness of policy implementation.

It is different from the original intention of the police to arbitrarily change the implementation scheme of a minimum living standard based on the special situation of the village or considering the local specific situation. Its actual aim is to seek private interests and replace the original policy content or append inappropriate policy content for the self-interest. ${ }^{[3]}$ The grassroots staff added their own relatives to the ranks of the household enjoying the minimum living guarantee and tamed with and replaced the original policy content with the banner of "combining with local realities". The standardization of the original standard was upgraded or lowered, and the conditions for the entry of the subsistence allowances were changed. This made the Rural Minimum Living Standard Guarantee System a tool of "tailor-made" for a few people, thereby losing the welfare and fairness of the rural subsistence allowance system.

2) The authority of the implementation of the Rural Minimum Living Standard Guarantee System is relatively weak.

Unlike the taxation system, the implementation of the taxation system is based on the support and guarantee of the national law. Moreover, the system itself is compulsory, and the cost of illegality is high. This makes the taxation system deterrent, and the executive department can implement the policy readily. Contrary to the taxation system, for the Rural Minimum Living Standard Guarantee System, the policy is primarily to rationally allocate social welfare resources to rural vulnerable groups. The actual objective of the policy is to help rural vulnerable groups to overcome difficulties and maintain their basic lives. The original intention of this morality makes it difficult for the policy to be supported by mandatory rights. The legal system is relatively weak, and there exists a vacuum of rights. However, the peasants have high demand for the subsistence allowance system and strong individual possession of public resources. The contrast between the strong and the weak highlights the weak authority of the service-oriented government. [4]

III. PROBLEMS FACED BY PEASANTS' PARTICIPATION IN THE RuRal Minimum Living Standard Guarantee System

\section{A. Self-Interest of Peasants' Interests}

For peasants with policy needs for the Rural Minimum Living Standard Guarantee System, as the target group of public policies, they are also characterized by the rational "economic man", that is, they also have their own interests in the process of policy formulation and implementation ${ }^{[5]}$. The target group of policy, also as a peasant, is influenced by traditional value ethics and living standards. Besides, its demand for public goods is always endless. In the face of high welfare, high value-added subsistence allowance system, peasantries will become increasingly selfish. The awareness is more obvious. For the rural subsistence allowance system of the socialized redistributive policy, the main content of the policy is the rational allocation and transfer of existing resources, which is more likely to cause the target groups to fight for interests by hook or by crook, or even moral bankruptcy. ${ }^{[6]}$

B. The Process of Democratic Appraisal is Disorderly, And the form of Expression of Willingness of Peasants is Backward and Scattered.

1) The disorder of the democratic appraisal processes.

Many villages are in the household enjoying the minimum living guarantees' parliament because of the influence of various parties, and the sectarians are in power. In addition to the normal "two committees" management institutions in the village, there are also restrictions on the surname, blood, and religious relations. And even superior leaders also meddled in democratic reviews for better management.. A democratic council involving the distribution of interests will often become a "gladiatorial arena" where all parties compete for interests. The appraisal scene presents a "one pot of porridge" situation, and the order is extremely poor. In the face of the Rural Minimum Living Standard Guarantee System, its high welfare characteristics will inevitably be the focus of the interests of all parties.

2) The way peasants participate is backward and decentralized.

At present, the agricultural society is in the transition period, with the rapid growth of production factors and the constant change of production relations, farmers' demands and 
interests are gradually diversified. In the rural subsistence allowance system operation process, involves the object is extensive and intricate. There is no clear direction of interest, and the level of interest pursuit is also different. Moreover, the lack of rural organizations is serious, and there is a lack of villager organizations that can represent their own interests. ${ }^{[7]}$ This diversified interest structure makes the democratic review unable to find the ideal meeting point. The participation of villagers in rural subsistence allowance is limited to individual participation, with low participation ability and influence degree, which seriously affects the effectiveness of democratic review.

\section{Peasants' Groups Have Insufficient Understanding of Policies}

1) Lead peasants to participate in the subsistence allowance system passively.

The quality of the peasant group includes personal education level, social experience, interpersonal communication, legal awareness, moral cultivation, etc. At this stage, the degree of participation of Chinese peasants in political life is overall low, and the passive characteristics of participating in political life. Obviously, one of the main reasons for the low level of participation of peasants is the quality of peasants themselves. Most peasants do not realize the political significance of a fair and reasonable democratic assessment. Peasants passively participate in the subsistence allowance system, especially the subsistence allowances council. Although they can choose the household enjoying the minimum living guarantee, compared with taking the initiative to participate in democratic evaluation and maintain the fairness and justice of the subsistence allowance system, their efficiency of the evaluation is lower. ${ }^{[8]}$

2) Lead peasants to misunderstand the subsistence allowance policy.

Nowadays, most peasants in China still have a low level of understanding of the Rural Minimum Living Standard Guarantee System. It is difficult for ordinary peasants to answer the basic questions e.g., the policy connotation and enjoyment of the Rural Minimum Living Standard Guarantee System. Besides, the household enjoying the minimum living guarantees know much less about the policy. Some household enjoying the minimum living guarantors understand the Rural Minimum Living Standard Guarantee System wrongly. They consider the Rural Minimum Living Standard Guarantee System as a long-term tenure system. Once it is acquired, it can be enjoyed for life, and eventually it will cause serious welfare dependence. This serious inadequate understanding of the policy has increased the burden on the exit mechanism and dynamic management level of the Rural Minimum Living Standard Guarantee System, and it is prone to illegal activities e.g., fraud insurance. ${ }^{[9]}$

\section{The Position of Power Between the Various Subjects is} Vague, and it is Easy to Lead to the Intersection of Rights and the Vacuum of Rights, Affecting the Role of Policies.

In the diversified grassroots governance mode of peasants participating in the Rural Minimum Living Standard Guarantee System, special attention should be paid to the division of rights of boundaries among the main bodies, as the current peasants participate in the democratic appraisal of the poverty-stricken households. The "person" feature inevitably carries the characteristics of a spontaneous "economic man". Higher -level governments, village officials, and official and non-official social organizations, more or less spontaneously intervene in the process and results of the review, making the review lack of impartiality, democratic appraisal become a mere formality. In the process of appraisal, the responsibilities of each subject are vague, and there exists the repeated governance and the intersection of power and responsibility. When peasants participate in the formulation of the Rural Minimum Living Standard Guarantee System and appraise the household enjoying the minimum living guarantee. if policy-making and implementing parties continue to adopt traditional Regulatory, exclusive and imperative policy development and implementation means to promote the operation of the Rural Minimum Living Standard Guarantee System. It is difficult to make the Rural Minimum Living Standard Guarantee System accept public opinion, build consensus, make the peasant participation system inefficient, and even lead peasants to participate in the Rural Minimum Living Standard Guarantee System bankruptcy. ${ }^{[10]}$

\section{COUNTERMEASURE AND SUGGESTION}

\section{A. Promoting the Construction of Modern Democratization in} Rural Society, Raising the Level of Peasants' Political Participation, and Promoting the Transformation of Peasants from Marginalized Participation to Core Participation

As with government governance, farmer participation also requires institutional, orderly and participatory democracy. If the farmers' participation in the lacked democracy, it will not only discourage the farmers' participation, but also seriously affect the long-established concept of farmer democracy.

Fully exploiting Internet platforms, e.g., Internet +, Microblog and We Chat, to attract peasants, establish online comment platforms, widely absorb their opinions and questions and actively adopt feasibility opinions; timely analyze the problems raised by peasants, and promptly rectify and feedback. Avoid peasants' participation in mere formality. Fully exploiting the villagers' councils and village meetings as platforms for rural participation in the construction of the rural subsistence allowance system. Strengthening institutionalization and standardization ensures that the issues are standardized and reasonable and combine them with the scheme of guaranteeing minimum living standards for village, and smooth access to information and reflection channels for peasants. 


\section{B. Improving the Level of Government Services, Innovating the Governance Model, and Seeking Common Ground and Governance}

1) Following the construction of "service-oriented governance" as a development direction, transforming administrative methods and playing a service-oriented governance role in the construction and operation of ensuring minimum living standard system.

The government should establish the main position of peasants. The needs of target groups should be fully considered in the choice and policy formulation of household enjoying the minimum living guarantee. In formulating policies and implementing norms, relevant norms should be formulated through consultation with peasant organizations or social organizations formed by them. We will actively establish consultation platforms and carefully design consultation procedures so that government decision-making can effectively absorb peasants' opinions and hear their voices. ${ }^{[11]}$

2) Clarify the boundary of rights and establish a rural subsistence network system based on "co-governance"

Taking the construction of "service-oriented governance" as the model, we should transform the administrative mode and play the role of service-oriented governance in the construction and operation of rural subsistence allowance system When setting up a network of peasants participating in the Rural Minimum Living Standard Guarantee System, In the selection of low-income households and the formulation of policies, the needs of target groups should be fully considered. When formulating policies and implementing regulations, relevant norms should be established through consultation with farmers or social organizations composed of farmers groups. We will actively set up consultation platforms and carefully design consultation procedures so that the government can effectively absorb the opinions of farmers and hear their voices. ${ }^{[12]}$ In the process of peasants participating in the construction of the Rural Minimum Living Standard Guarantee system, the government must maintain the role of "Meta-governance" in the construction process and coordinate the formulation and implementation of the operating mechanism of the Rural Minimum Living Standard Guarantee, the level of subsidies, the selection conditions and the strategic development of policies, and the long-term planning. When the farmers participate in the failure, we should do a good job and complete the work to prevent more serious consequences caused by the failure of the system. At the beginning of their participation, peasants can elect representatives of villagers who can represent their own wishes and form social organizations that specialize in democratic deliberation to comment on household enjoying the minimum living guarantee. As the level of peasants' participation continues to increase, after the peasants' organizations have a general grasp of the policies and the evaluation targets are accurate and conform to the wishes of all parties. Allow peasants' groups to participate in draw up implementation standards and evaluation standards. After intensive discussions in the form of village meetings, from a proposal and feed it back to the government.

\section{Establishing an Effective Platform for Peasants to Assess, Collect Information and Feedback on the Rural Minimum Living Standard Guarantee System, with the Support of Social Organizations}

In the early stages of peasants' participation in the construction of the Rural Minimum Living Standard Guarantee System, village-level deliberation organizations can be formed by election representatives. Take a group of villagers as a unit, each representative is responsible for a group, and communicate with each villager in the group in a timely manner to collect practical information about the construction of the Rural Minimum Living Standard Guarantee system. Fully use the information-based social organizations to collect information on analysis and processing of household enjoying the minimum living guarantee assessment work, e.g., third-party assessment organizations to specialize low-income and poor households according to evaluation indicators Evaluation can be used as an important reference when democratically reviewing household enjoying the minimum living guarantee.

\section{Strengthen Publicity, Raise Peasants' Understanding and \\ Understanding of Rural Minimum Living Standard \\ Guarantee, Raise the Level of Peasants' Political \\ Participation, and Promote the Shift from Marginalized \\ Participation to core Participation}

Publicize the advantages of participatory governance and Rural Minimum Living Standard Guarantee system construction to farmers and mobilize them to participate; Regular seminars on rural subsistence policies to disseminate knowledge about Rural Minimum Living Standard Guarantee System; relying on microblog, We Chat and other social medias, establish a network promotion tool. E.g., the establishment of Rural Minimum Living Standard Guarantee We Chat official account at the village level, regular promotion of Rural Minimum Living Standard Guarantee related articles to the villagers to publicize rural minimum living standard guarantee information, the relevant national system, and the basic procedures for peasants to participate in the construction of rural minimum living standard guarantee systems. Help farmers understand the importance of Rural Minimum Living Standard Guarantee and its relationship with themselves and promote farmers to actively participate in the construction of Rural Minimum Living Standard Guarantee system.

\section{CONCLUSION}

In summary, the Rural Minimum-Security System, as one of the basic social security systems in rural areas, although cannot fundamentally solve the problem of poverty, it could alleviate the livelihood problem of the poor most promptly and directly. This is beyond the reach of other rural social security policies. ${ }^{[13]}$ As for the introduction of peasant participation in the construction of the rural minimum-security system, it is not only a complement to the policy itself, but also makes peasants realize that the rural subsistence allowance is not an empty talk. The formulation and implementation of the minimum-security policy require profound political trade-offs and considerations. More profoundly, the participation of peasants in the construction of the rural minimum-security system is more conducive to cultivating peasants' awareness and ability of political participation and shaping modern peasants. To lay a deep practical foundation for the realization of service-oriented governance, the construction of 
modern governance system and the overall transformation of rural grass-roots ethical concepts and culture. ${ }^{[14]}$

\section{REFERENCES}

[1] Yin Zi. Rural basic governance unit and its governance capacity construction [J/OL]. Journal of South China Agricultural University (Social Science Edition), 2018 (03): 107-114 (In Chinese)

[2] Ge Liting. The Dilemma and Breakthrough of the Implementation of Rural Minimum-Security System [J]. Journal of Qingdao Municipal Party Committee. Journal of Qingdao Administrative College, 2017(06):110-114. (In Chinese)

[3] Zhao Fuke. Exploring the problem of policy avoidance in the implementation of public policy[J]. Journal of Shandong University of Technology (Social Science Edition), 2004(04): 39-42. (In Chinese)

[4] Yin Zi. Two Types of Formation Variables in the Practice Deviation of Low-income Policy-Comment on the Theory of Farmers Participation in Public Policy Implementation[J].Journal of Party School of Ningbo Municipal Committee,2014,36(01):67-74. (In Chinese)

[5] Gao Jianhua. Analysis of the Factors of Policy Target Group Affecting the Effective Implementation of Public Policies [J]. Academic Forum, 2007 (06): 53-57. (In Chinese)
[6] Wei Wei. Policy Types and Policy Implementation: An Empirical Study Based on Multiple Case Comparisons[J]. Nanjing Social Sciences, 2012(05): 55-63. (In Chinese)

[7] Zhu Zhe, Chen Jian, Jin Guohua. Analysis of the Development Path of Grassroots Consultative Democracy in Rural China[J]. Theoretical Discussion, 2015(06): 28-31. (In Chinese)

[8] Fang Fei, Li Huazhen. Discussion on the Ethical Loss of Rural Minimum Living Security System and Its Correction[J].Realistic,2010(08):89-92. (In Chinese)

[9] Li Chungen, Liao Yan. On the construction of the credit mechanism of rural minimum living security objects under the background of precision poverty alleviation[J].Shandong Social Sciences, 2018(03):67-73. (In Chinese)

[10] Shu Guang, Li Guangwen. Public Affairs Negotiation Mechanism in the Process of Diversified Governance[J]. Exploration, 2014(06): 69-74. (In Chinese)

[11] Chen Zhenming. Policy Science [M]. Beijing: China Renmin University Press, 1998.318) (In Chinese)

[12] Zhang Jun. Diversification of Rural Governance from the Perspective of Rural Contradictions-Taking Liang Zhai Town, Feng County, Jiangsu Province as an Example[J]. Journal of Jiangsu Normal University (Philosophy and Social Sciences), 2017, 43(04):15 -20. (In Chinese)

[13] Sun Rui. Research on rural minimum living security [D]. Shandong Agricultural University, 2012. (In Chinese)

[14] Zhu Zhe, Shi Bo, Bao Agu Da mu. Problems and Countermeasures in the Construction of Rural Grassroots Consultative Democracy System[J]. Theoretical Discussion, 2016(06): 16-21. (In Chinese) 